\title{
3rd International IUPAC Symposium on Trace Elements in Food (TEF-3)
}

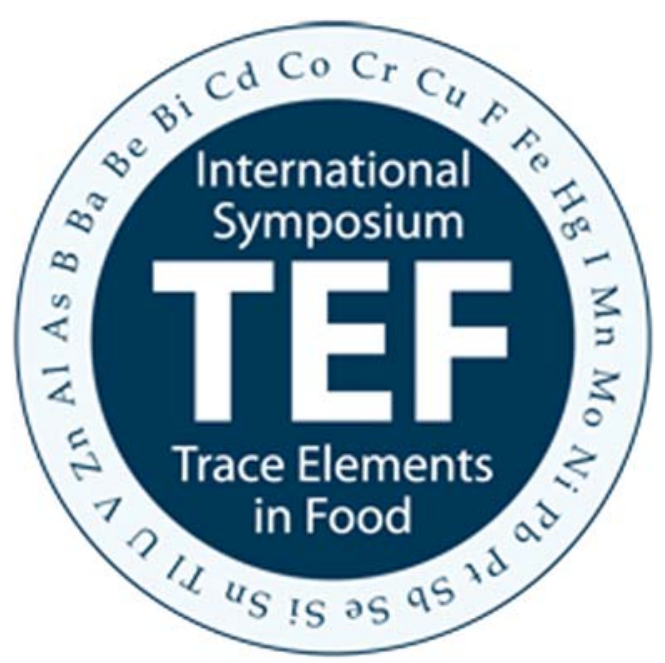

The 3rd International IUPAC Symposium on Trace Elements in Food (TEF-3) will be held on 1-3 April 2009 in Rome, Italy, organized by the Istituto Superiore di Sanità. The meeting will consist of two and a half days of oral and poster presentations. Plenary lectures will be given by invited speakers in the following areas:

- Advances in trace element analysis in food matrices

- Sources and transfer of trace elements in the food chain

- Toxicology and risk assessment

- Trace element nutrition and human health.

The objective of this interdisciplinary symposium is to gather experts with different backgrounds to discuss all aspects of trace elements in relation to food, with special emphasis on biological effects of elements. The topics covered include essentiality, toxicity, bioaccessibility, bioavailability, speciation, sources and transfer in the food chain, effects of processing, food fortification, supplementation, international legislation and standards, analytical developments, analytical quality assurance and reference materials. Special emphasis will be placed on research and development efforts which have taken place in the last few years as well as on emerging issues in the area.

This meeting follows the previous ones, organized in Warsaw, Poland (2000), and in Brussels, Belgium (2004). Like the two previous meetings of this series, TEF-3 aims at being a suitable forum for new ideas and experiences to be exchanged among researchers in the trace element area with a view to providing an evidence base for policy, advice on the development of improved foods and riskmanagement tools to protect public health.

\section{Important dates}

Deadline for preregistration: 30 September 2008

Deadline for submission of abstracts: 1 December 2008

Deadline for reduced fee payment: 15 January 2009

\section{Information}

Further details are available on the symposium website (http://www.tef3-2009.it).

Symposium Chair: Dr. Francesco Cubadda, Instituto Superiore di Sanità, Viale Regina Elena 299, 00161 Rome, Italy.

Tel.: +39-06-49903643; Fax: +39-06-49902540; e-mail: francesco.cubadda@iss.it 